\title{
ESTRUTURA DO DOSSEL E CARACTERÍSTICAS DE PERFILHOS EM PASTOS DE CAPIM-PIATÃ MANEJADOS COM DOSES DE NITROGÊNIO E PERÍODOS DE DIFERIMENTO VARIÁVEIS
}

\section{SWARD STRUCTURE AND TILLER CHARACTERISTICS IN PIATÃ GRASS PASTURES MANAGED WITH VARIABLE NITROGEN DOSES AND DEFERMENT PERIODS}

\author{
Manoel Eduardo Rozalino Santos ${ }^{1 *}$ \\ Braulio Maia de Lana Sousa ${ }^{2}$ \\ Gabriel de Oliveira Rocha ${ }^{3}$ \\ Cássia Aparecida Soares Freitas ${ }^{3}$ \\ Márcia Cristina Teixeira da Silveira ${ }^{4}$ \\ Diogo Olímpio Chaves de Sousa ${ }^{1}$ \\ 1Universidade Federal de Uberlândia, Uberlândia, MG, Brasil.
Universidade Federal de Sergipe, Aracaju, SE, Brasil.
${ }^{3}$ Universidade Federal de Viçosa, Viçosa, MG, Brasil.
${ }^{4}$ Empresa Brasileira de Pesquisa Agropecuária, EMBRAPA, Bagé, RS, Brasil.
${ }^{\star}$ Autor para correspondência - manoel.rozalino@ufu.br
}

\section{Resumo}

Este trabalho foi desenvolvido de 25 de fevereiro a 01 de julho de 2012 para recomendar a(s) dose(s) de nitrogênio e o(s) período(s) de diferimento que resultam em pastos diferidos de Brachiaria brizantha cv. Piatã (capim-piatã) com características estruturais adequadas ao consumo animal. Foram avaliadas combinações entre períodos de diferimento e condições de adubação nitrogenada. Os períodos de diferimento foram longo (127 dias) e curto (79 dias). As doses de nitrogênio foram de 0, 40, 80 e $120 \mathrm{~kg} / \mathrm{ha}$. O delineamento experimental foi de blocos casualizados, com três repetições. O índice de área foliar (IAF) e a interceptação luminosa (IL) aumentaram com a aplicação de nitrogênio. Na ausência ou dose pequena de nitrogênio, o pasto diferido por curto período apresentou IAF e IL inferiores ao manejado com longo período de diferimento. A dose de nitrogênio só influenciou a densidade de perfilhos basais vegetativos. O menor período de diferimento resultou em maiores números de perfilhos basais e aéreos vegetativos, assim como número inferior de perfilho basal reprodutivo. O nitrogênio aumentou o comprimento da lâmina foliar e do colmo do perfilho vegetativo. Longo período de diferimento resultou em colmo e lâmina 
foliar mais compridos e maior número de folhas mortas. $\mathrm{O}$ capim-piatã pode ser diferido por 80 dias, com aplicação de $80 \mathrm{~kg} /$ ha de nitrogênio no início do período de diferimento.

Palavras-chave: Brachiaria brizantha; colmo; folha; índice de área foliar; interceptação luminosa.

\begin{abstract}
This study was conducted from Feb. 25 $5^{\text {th }}, 2012$ to Jul. $1^{\text {st }}, 2012$ to recommend nitrogen doses and deferment periods that result in deferred Brachiaria brizantha cv. Piatã (piatã grass) pastures with structural characteristics suitable for animal consumption. Combinations were evaluated between deferment periods and nitrogen fertilization conditions. The deferment periods were long (127 days) and short (79 days). Nitrogen doses were $0,40,80$, and $120 \mathrm{~kg} / \mathrm{ha}$. The experimental design was a randomized block with three replications. The leaf area index (LAI) and light interception (LI) increased with the application of nitrogen. In the absence or at a small nitrogen dose, pasture deferred for short periods presented lower LAI and LI than pasture managed with long deferment period. The nitrogen only influenced the density of vegetative basal tillers. The lower deferment period resulted in a greater number of basal tillers and vegetative air, as well as fewer reproductive basal tillers. Nitrogen increased the length of the leaf blade and the vegetative tiller stem. Long deferral period resulted in longer stem and leaf blade and a larger number of dead leaves. Piatã grass can be deferred for 80 days, with application of $80 \mathrm{~kg} / \mathrm{ha}$ of nitrogen at the beginning of the deferment period.
\end{abstract}

Keywords: Brachiaria brizantha; leaf; leaf area index; light interception; stem.

Recebido em: 03 setembro de 2015

Aceito em: 05 junho de 2017

\title{
Introdução
}

Em sistemas de produção animal baseados na utilização de pastagens, um princípio básico deve ser atendido, qual seja: a produção de forragem (suprimento) deve ser equilibrada com o consumo de pasto pelo rebanho (demanda). Esse princípio é mais facilmente alcançado, nas regiões Sudeste e Centro-Oeste do Brasil, durante os meses de primavera e verão, quando as taxas de crescimento das gramíneas tropicais são altas ${ }^{(1-3)}$. Por outro lado, durante os meses de outono e inverno, a relação suprimento/demanda de forragem em pastagem é baixa, o que tem consequências negativas sobre a produtividade animal em pastagens.

Dentre as alternativas técnicas para garantir suprimento de forragem ao rebanho no inverno, destaca-se o diferimento do uso da pastagem, uma alternativa relativamente fácil e de baixo custo. O diferimento do uso da pastagem consiste em retirar os animais de determinada área de pastagem, em geral no outono, para que o pasto se desenvolva e, com isso, se forme um estoque de forragem para ser utilizado, sob pastejo, durante o inverno ${ }^{(4,5)}$.

Dentre as possibilidades de recursos forrageiros, a Brachiaria brizantha cv. Piatã (capim-piatã) é apropriada para uso em pastagens diferidas, pois possui baixa altura natural, colmo pouco espesso e não apresenta florescimento concentrado durante os meses de outono em que, normalmente, o pasto 
permanece diferido ${ }^{(3)}$. Esses fatores contribuem para a que o pasto diferido de capim-piatã apresente estrutura favorável ao consumo animal, desde que ações adequadas de manejo sejam implementadas, tal como o controle do período de diferimento e o uso de adubos nitrogenados.

O período de diferimento, isto é, o tempo em que o pasto fica sem animais e, portanto, em crescimento livre, deve garantir produção de forragem em quantidade suficiente para alimentar o rebanho no inverno, sem prejudicar as características estruturais do pasto diferido. Assim, por meio da alteração do período de diferimento, objetiva-se que o pasto diferido tenha alta percentagem de perfilhos vegetativos em detrimentos dos reprodutivos, e perfilhos vegetativos com colmos mais curtos e poucas folhas mortas. Essas características estruturais resultam em um pasto de melhor valor nutritivo para os ruminantes ${ }^{(6)}$.

A taxa de crescimento do pasto deve ser considerada para a correta escolha do período de diferimento. Desse modo, pastos com altas taxas de crescimento devem permanecer diferidos por período mais curto, contrariamente àqueles com menores taxas de desenvolvimentos para garantir quantidade de pasto com características estruturais adequadas. Nesse sentido, considerando-se que o nitrogênio $(\mathrm{N})$ estimula o crescimento das gramíneas tropicais ${ }^{(2,7)}$, o período de diferimento deve ser controlado de acordo a estratégia de adubação nitrogenada utilizada em pastagens diferidas ${ }^{(8)}$.

Em dosséis forrageiros com baixo índice de área foliar (IAF), o $\mathrm{N}$ aumenta o aparecimento de perfilhos $^{(1)}$, tornando o dossel mais denso. Para que esse efeito ocorra em pastagens diferidas, a aplicação de $\mathrm{N}$ deve ocorrer antes ou no dia do início do diferimento, quando o solo ainda encontrase com adequada umidade ${ }^{(8)}$. Todavia, em dosséis com alto IAF, tal como naqueles diferidos por longo período, o $\mathrm{N}$ pode aumentar o desenvolvimento das plantas e, com isso, resultar em maior sombreamento no interior do dossel, o que inibe o perfilhamento ${ }^{(9)}$.

Com base no exposto, existe a hipótese de que o capim-piatã sob maior período de diferimento e adubado com maiores doses de nitrogênio apresente maiores IAF e interceptação de luz, o que pode causar a redução do número de perfilhos vegetativos no dossel. Por outro lado, nestas condições, é provável que o capim-piatã apresente maior número de perfilho reprodutivo, bem como perfilhos mais compridos e com mais folhas mortas.

Este estudo foi desenvolvido para recomendar a(s) dose(s) de nitrogênio e o(s) período(s) de diferimento que resultam em pastos diferidos de capim-piatã com características estruturais adequadas ao consumo animal.

\section{Material e Métodos}

O experimento foi realizado de 25 de fevereiro a 01 de julho de 2012 no Setor de Forragicultura do Departamento de Zootecnia, na Universidade Federal de Viçosa (UFV), localizada em Viçosa, MG, ( $20^{\circ} 45^{\prime}$ de latitude Sul e $42^{\circ} 51^{\prime}$ de longitude Oeste e $651 \mathrm{~m}$ de altitude). Foi utilizada uma área com capim-piatã de $240 \mathrm{~m}^{2}$, estabelecida em 2009 em um Latossolo Vermelho-Amarelo de textura $\operatorname{argilosa}^{(10)}$. 
Segundo a classificação de Köppen ${ }^{(11)}$, o clima da região é do tipo Cwa, com precipitação anual em torno de $1.340 \mathrm{~mm}$, umidade relativa do ar média de $80 \%$ e temperatura média de $19,0{ }^{\circ} \mathrm{C}$. Os períodos seco (maio a outubro) e chuvoso (novembro a abril) são bem definidos nesta região. Os dados climáticos registrados durante o período experimental foram obtidos na estação meteorológica do Departamento de Engenharia Agrícola da UFV, situada a cerca de $1.000 \mathrm{~m}$ da área experimental (Tabela 1).

Tabela 1. Médias mensais das temperaturas mínima, média e máxima diárias, precipitação pluvial e evaporação total mensal no período de fevereiro a julho de 2012

\begin{tabular}{ccccc}
\hline Mês & $\begin{array}{c}\text { Temperatura } \\
\text { média }\left({ }^{\circ} \mathrm{C}\right)\end{array}$ & $\begin{array}{c}\text { Temperatura } \\
\text { mínima }\left({ }^{\circ} \mathrm{C}\right)\end{array}$ & $\begin{array}{c}\text { Temperatura } \\
\text { máxima }\left({ }^{\circ} \mathrm{C}\right)\end{array}$ & $\begin{array}{c}\text { Precipitação } \\
\text { pluvial }(\mathrm{mm})\end{array}$ \\
\hline Fevereiro & 22,5 & 18,2 & 29,7 & 41,1 \\
Março & 21,5 & 18,0 & 29,4 & 112,0 \\
Abril & 19,9 & 17,3 & 28,9 & 52,0 \\
Maio & 18,1 & 14,8 & 23,9 & 120,0 \\
Junho & 18,3 & 14,8 & 24,1 & 12,0 \\
Julho & 17,8 & 14,6 & 25,0 & 5,0 \\
\hline
\end{tabular}

Conforme resultados da análise química, realizada no início do período experimental, na camada de 0 a $20 \mathrm{~cm}$, o solo apresentava as seguintes características: $\mathrm{pH}$ em $\mathrm{H}_{2} \mathrm{O}$ : 5,50; $\mathrm{P}$ (Mehlich-1): 1,40 $\mathrm{mg} / \mathrm{dm}^{3}$ e K: 36,00 mg/dm $; \mathrm{Ca}^{2+}: 2,10 \mathrm{cmol}_{\mathrm{c}} / \mathrm{dm}^{3} ; \mathrm{Mg}^{2+}: 0,70 \mathrm{cmol}_{\mathrm{c}} / \mathrm{dm}^{3}$ e $\mathrm{Al}^{3+}: 0,00 \mathrm{cmol}_{\mathrm{c}} / \mathrm{dm}^{3}$ ( $\mathrm{KCl} 1 \mathrm{~mol} / \mathrm{L})$. Com base nesses resultados, não foi necessário realizar a calagem. No início de cada período de diferimento, aplicaram-se $60 \mathrm{~kg} / \mathrm{ha}$ de fósforo na forma de superfosfato simples e 60 $\mathrm{kg} / \mathrm{ha}$ potássio na forma de cloreto de potássio, em dose única e ao final da tarde.

Foram avaliadas combinações entre períodos de diferimento e condições de adubação nitrogenada. Os períodos de diferimento foram longo (127 dias) e curto (79 dias). Assim, o diferimento ocorreu nos dias 25 de fevereiro e 25 de abril, permanecendo o capim-piatã vedado até o dia 01 de julho, para que os períodos longo e curto fossem gerados. As doses de nitrogênio foram de 40, 80 e 120 $\mathrm{kg} / \mathrm{ha}$ mais um controle sem nitrogênio (0 kg/ha). Foi utilizado o delineamento em blocos completos casualizados com três repetições, em um esquema de parcelas subdivididas. $\mathrm{O}$ critério utilizado para a definição dos blocos foi a variação do relevo da área experimental.

No início de cada período de diferimento, o capim-piatã foi rebaixado para $20 \mathrm{~cm}$ de altura ${ }^{(12,13)}$ por meio de corte mecânico. Nessa data, também foram aplicadas, em dose única e ao final da tarde, as doses de nitrogênio na forma de ureia agrícola para redução das perdas por volatilização. Após a adubação e apenas no primeiro dia do período experimental, a área foi molhada manualmente para elevar a umidade do solo e aumentar a eficiência do uso dos adubos. Com isso, objetivou-se simular um aporte de água ao solo correspondente a uma precipitação pluviométrica de $5 \mathrm{~mm}$. Essa estratégia também foi empregada para simular o que, normalmente, ocorre na prática, ou seja, a aplicação de adubos em pastagens no início do período de diferimento e após a ocorrência de chuvas, quando o solo ainda apresenta umidade satisfatória. O capim-piatã permaneceu diferido até o dia 01 de julho de 2012, data em que todas as avaliações foram realizadas.

As mensurações da interceptação luminosa pelo dossel, do índice de área da folhagem e do ângulo 
da folhagem (folhas, colmo e tecido morto) foram realizadas utilizando-se o Analisador de dossel LAI 2000 (LI-COR ${ }^{\circledR}$ ), em dois pontos aleatórios por unidade experimental. Em cada ponto, foram tomadas uma leitura acima do dossel e cinco na superfície do solo.

A avaliação do número de perfilhos foi realizada por meio da colheita de duas amostras, em pontos que representavam a altura média do dossel. Foram colhidos, com corte rente ao solo, todos os perfilhos contidos no interior de moldura de vergalhão de 0,25 m de lado. Esses perfilhos foram acondicionados em sacos plásticos identificados e, em seguida, levados para o laboratório, onde foram separados e quantificados em perfilhos basais ou aéreos e em perfilhos vegetativos ou reprodutivos. Considerou-se perfilho basal aquele oriundo de gemas localizadas próxima ou rente à superfície do solo. Os perfilhos aéreos correspondem àqueles originados de gemas laterais no perfilho basal principal. Os perfilhos vivos que tinham a inflorescência visível foram classificados como reprodutivos e os vivos que não tinham a inflorescência visível foram denominados de vegetativos.

As características estruturais foram avaliadas em dez perfilhos basais vegetativos e em dez reprodutivos, por unidade experimental. Nestes perfilhos foram quantificados os comprimentos do pseudocolmo e da lâmina foliar, bem como os números de folhas vivas e mortas. O comprimento do colmo foi mensurado desde o solo até a lígula da folha mais velha completamente expandida. O comprimento da lâmina foliar correspondeu ao comprimento médio das lâminas foliares expandidas. As folhas vivas consistiram de folhas em expansão e expandidas. Apenas as folhas que possuíam mais de $50 \%$ da lâmina foliar senescente foram classificadas como mortas.

A análise dos dados foi realizada utilizando-se o pacote estatístico SAEG (Sistema de Análises Estatísticas e Genéticas, versão 8.1) ${ }^{(14)}$. O conjunto de dados foi testado de forma a assegurar que as prerrogativas básicas da análise de variância fossem atendidas e, quando necessário, os dados foram transformados. Desse modo, a densidade populacional de perfilhos reprodutivos basais foi transformada para logaritmo de base $(10+0,5)$ para a realização da análise de variância. No entanto, para a apresentação dos resultados, foram utilizadas as médias dos valores não transformados. A densidade populacional de perfilhos reprodutivos aéreos, mesmo transformada, não atendeu aos pressupostos básicos da análise de variância e, por isso, foi analisada pela estatística não paramétrica.

Para o período de diferimento, fator qualitativo, a comparação entre as médias foi realizada pelo teste de Tukey. Para a adubação nitrogenada, fator quantitativo, foi realizada análise de regressão, considerando os modelos que melhor se ajustaram aos dados. Adotou-se o nível de significância de $5 \%$ de probabilidade de ocorrência do erro tipo I.

\section{Resultados e Discussão}

Independente do período de diferimento, o índice de área da folhagem (IAF) e a interceptação de 
luz pelo dossel (IL) aumentaram $(\mathrm{P}<0,05)$ de forma linear com a aplicação de nitrogênio (Tabela 2). O nitrogênio aumenta a divisão celular e o fluxo de tecidos dos perfilhos de gramíneas forrageiras tropicais, incrementando o aparecimento e o alongamento foliar ${ }^{(7,15)}$, com efeito positivo sobre o IAF e, consequentemente, a interceptação de luz pelo dossel.

A interceptação de luz pelas lâminas foliares em dossel de gramínea forrageira é premissa para ocorrência de fotossíntese e, com efeito, para o crescimento do pasto. No entanto, vale salientar que, no presente estudo, o IAF foi mensurado de forma indireta, por meio do Analisador de dossel LAI 2000. Com isso, é possível que tenha ocorrido uma superestimativa do IAF, na medida em que o sensor desse aparelho é incapaz de distinguir folhas de outras partes da planta, como colmos e tecidos mortos e, assim, toda a superfície da planta passível de contribuir para a interceptação de luz é considerada nos cálculos realizados pelo aparelho como área foliar ${ }^{(16)}$. Em pastos diferidos, onde a presença de colmo e tecidos mortos em geral é alta(4,12,13), o IAF pode ser superestimado.

Em pastos diferidos, o dossel geralmente intercepta altos níveis de radiação solar devido ao longo período de crescimento e, com isso, é comum que estes pastos possuam IAF superior ao crítico, condição em que a diferenciação morfológica do pasto é maior, haja vista que alongamento do colmo, bem como a senescência foliar, são acentuados ${ }^{(9,12,13)}$. De fato, dos oito pastos diferidos, resultado das combinações entre os dois períodos de diferimento e as quatro doses de nitrogênio avaliadas, apenas dois pastos apresentaram IL inferior a 95\%, ou seja, estavam com IAF inferior ao crítico (Tabela 2). Nesse sentido, o conceito de estrutura do pasto diferido adequada ao animal em pastejo deve ser contextualizado para condições de pastagens diferidas, na medida em que, no inverno, em virtude da alta escassez hídrica no solo, níveis altos de senescência foliar são inevitáveis ${ }^{(17)}$. Além disso, para obtenção de quantidade de forragem satisfatória na entressafra, o período de diferimento do pasto é longo quando cotejado com o período de descanso dos mesmos pastos manejados na primavera e no verão, o que aumenta o estádio de desenvolvimento da planta forrageira, com consequente maior participação de colmo e tecidos mortos no pasto ${ }^{(18)}$.

O nitrogênio aumentou mais pronunciadamente o IAF e a IL do pasto quando curto período de diferimento foi adotado. Realmente, os coeficientes angulares das equações ajustadas para IAF e a IL foram superiores nos pastos submetidos ao curto período de diferimento, em comparação àqueles sob longo período (Tabela 2).

No que diz respeito ao ângulo da folhagem, seu valor diminuiu $(\mathrm{P}<0,05)$ linearmente com a aplicação de nitrogênio (Tabela 2). O estímulo do nitrogênio ao desenvolvimento dos perfilhos resultou em lâminas foliares mais compridas e pesadas, o que promoveu a disposição mais horizontal desses órgãos na planta e, com efeito, menor ângulo foliar ${ }^{(19)}$. Isso ocorreu principalmente nos pastos diferidos com alta dose de nitrogênio (120 kg/ha) e longo período de diferimento. (Tabela 2).

Com a ausência ou aplicação de dose baixa de nitrogênio (40 kg/ha), o pasto diferido por curto período apresentou IAF e IL inferiores $(\mathrm{P}<0,05)$ em relação ao manejado com longo período de diferimento. Todavia, quando doses maiores de nitrogênio foram aplicadas (80 e $120 \mathrm{~kg} / \mathrm{ha}$ ), não houve $(\mathrm{P}>0,05)$ efeitos do período de diferimento sobre essas características (Tabela 2). A maior taxa de desenvolvimento do pasto adubado com altas doses de nitrogênio fez com que os efeitos do período de diferimento não fossem manifestados no IAF e IL do dossel. Porém, quando o pasto 
apresentou menor taxa de crescimento, devido à baixa disponibilidade de nitrogênio no solo, o longo período de diferimento garantiu mais tempo para a formação dos órgãos da parte aérea do pasto (folhas e colmos), o que resultou em IAF e IL do dossel superiores, em comparação aos pastos com curto período de diferimento.

Tabela 2. Estrutura do capim-piatã diferido em dois períodos e com quatro doses de nitrogênio

\begin{tabular}{|c|c|c|c|c|c|c|}
\hline \multirow{2}{*}{$\begin{array}{l}\text { Período de } \\
\text { diferimento }\end{array}$} & \multicolumn{4}{|c|}{ Dose de nitrogênio (kg/ha) } & \multirow{2}{*}{ Equação } & \multirow{2}{*}{$\mathbf{r}^{2}$} \\
\hline & 0 & 40 & 80 & 120 & & \\
\hline \multicolumn{7}{|c|}{ Índice de área da folhagem } \\
\hline Curto & $2,64 \mathrm{~b}$ & $3,41 \mathrm{~b}$ & $4,78 \mathrm{a}$ & $5,35 \mathrm{a}$ & $\hat{\mathrm{Y}}=2,619+0,02376^{*} \mathrm{~N}$ & 0,97 \\
\hline Longo & $4,19 \mathrm{a}$ & $4,69 \mathrm{a}$ & $5,12 \mathrm{a}$ & $5,98 \mathrm{a}$ & $\hat{\mathrm{Y}}=4,125+0,01447^{*} \mathrm{~N}$ & 0,97 \\
\hline \multicolumn{7}{|c|}{ Interceptação luminosa (\%) } \\
\hline Curto & $86,4 \mathrm{~b}$ & $92,0 \mathrm{~b}$ & $97,4 \mathrm{a}$ & $98,1 \mathrm{a}$ & $\hat{\mathrm{Y}}=87,433+0,1008^{*} \mathrm{~N}$ & 0,92 \\
\hline Longo & $95,5 \mathrm{a}$ & $96,9 \mathrm{a}$ & 98,1 a & 99,1 a & $\hat{\mathrm{Y}}=95,617+0,02958^{*} \mathrm{~N}$ & 0,99 \\
\hline \multicolumn{7}{|c|}{ Ângulo da folhagem (grau) } \\
\hline Curto & $52,0 \mathrm{a}$ & $50,7 \mathrm{a}$ & 44,3 a & $47,0 \mathrm{a}$ & $\hat{\mathrm{Y}}=51,700-0,05333^{*} \mathrm{~N}$ & 0,62 \\
\hline Longo & $49,7 \mathrm{a}$ & $47,3 \mathrm{a}$ & $43,3 \mathrm{a}$ & $38,3 \mathrm{~b}$ & $\hat{\mathrm{Y}}=50,367-0,0950^{*} \mathrm{~N}$ & 0,98 \\
\hline
\end{tabular}

As variações em IAF e IL causam modificações no ambiente luminoso do dossel, com consequência sobre os padrões de perfilhamento do pasto diferido ${ }^{(9)}$. Isso justifica o padrão de resposta quadrático $(\mathrm{P}<0,05)$ da densidade populacional de perfilhos basais vegetativos em função da aplicação de nitrogênio em pasto manejado com curto período de diferimento (Tabela 3). Com base na equação ajustada, o número de perfilhos basais vegetativos aumentou até o ponto de máximo de 726 perfilhos $/ \mathrm{m}^{2}$, com aplicação de $88 \mathrm{~kg} /$ ha de nitrogênio. A partir desse nível de adubo, o número de perfilho decresceu.

Com curto período de diferimento, a aplicação de nitrogênio até níveis médios faz com que o IAF e a IL do pasto sejam incrementados de forma moderada, sem promover sombreamento intenso no interior do dossel (Tabela 3). Essa condição garante maior quantidade e qualidade de luz que chega até a base do dossel, o que estimula o desenvolvimento das gemas basais em novos perfilhos e potencializa o efeito positivo do nitrogênio sobre o aparecimento de perfilhos ${ }^{(20)}$.

O nitrogênio aumenta a taxa de aparecimento foliar em gramíneas forrageiras tropicais ${ }^{(7,15,20)}$. Dessa forma, como toda folha formada indica o surgimento de um novo fitômero, que contém, dentre outros órgãos, uma gema axilar, a alta taxa de aparecimento foliar, típica de pastos adubados com nitrogênio, também resulta em alta taxa de aparecimento de gemas axilares no pasto. Estas, em condições de menor sombreamento, podem se desenvolver em novos perfilhos. Esse mecanismo pode explicar o incremento do número de perfilhos vegetativos em pastos adubados com até 88 kg/ha de nitrogênio.

Por outro lado, quando doses mais altas de nitrogênio são aplicadas, o desenvolvimento do pasto diferido é mais acentuado e seus IAF e IL aumentam demasiadamente (Tabela 2). Essa situação gera alto nível de sombreamento no interior do dossel, com efeitos negativos sobre o perfilhamento. 
Realmente, em pastos com alto IAF e baixa IL, o desenvolvimento de novos perfilhos é inibido em razão da baixa quantidade e qualidade de luz que incide sobre as gemas basais ${ }^{(21,22)}$. Dessa maneira, o pasto prioriza o desenvolvimento dos perfilhos mais velhos em detrimento de novos perfilhos, o que tem consequências sobre as características estruturais dos perfilhos e, logo, dos pastos diferidos.

Tabela 3. Densidade populacional de perfilhos (perfilhos $/ \mathrm{m}^{2}$ ) do capim-piatã diferido em dois períodos e com quatro doses de nitrogênio

\begin{tabular}{|c|c|c|c|c|c|c|}
\hline \multirow{2}{*}{$\begin{array}{l}\text { Período de } \\
\text { diferimento }\end{array}$} & \multicolumn{4}{|c|}{ Dose de nitrogênio (kg/ha) } & \multirow{2}{*}{ Equação } & \multirow{2}{*}{$\mathbf{r}^{2}$} \\
\hline & 0 & 40 & 80 & 120 & & \\
\hline \multicolumn{7}{|c|}{ Densidade populacional de perfilhos basais vegetativos } \\
\hline Curto & 356,3 a & $685,4 \mathrm{a}$ & $660,4 \mathrm{a}$ & $700,0 \mathrm{a}$ & $\hat{\mathrm{Y}}=377,21+7,9451 * \mathrm{~N}-0,0452 * \mathrm{~N}^{2}$ & 0,89 \\
\hline Longo & 214,6 a & $225,0 \mathrm{~b}$ & $258,3 \mathrm{~b}$ & $227,1 \mathrm{~b}$ & $\bar{Y}=231,3$ & - \\
\hline \multicolumn{7}{|c|}{ Densidade populacional de perfilhos basais reprodutivos ${ }^{1}$} \\
\hline Curto & $27,1 \mathrm{~b}$ & $14,6 \mathrm{~b}$ & $10,4 \mathrm{~b}$ & $10,4 \mathrm{~b}$ & $\bar{Y}=15,6$ & - \\
\hline Longo & $170,8 \mathrm{a}$ & $162,5 \mathrm{a}$ & 193,8 a & $241,7 \mathrm{a}$ & $\bar{Y}=192,2$ & - \\
\hline \multicolumn{7}{|c|}{ Densidade populacional de perfilhos aéreos vegetativos } \\
\hline Curto & 193,8 a & $175,0 \mathrm{a}$ & $204,2 \mathrm{a}$ & $210,4 \mathrm{a}$ & $\bar{Y}=195,8$ & - \\
\hline Longo & $0,0 \mathrm{~b}$ & $4,2 \mathrm{~b}$ & $10,4 \mathrm{~b}$ & $8,3 \mathrm{~b}$ & $\bar{Y}=5,7$ & - \\
\hline
\end{tabular}

As demais categorias de perfilhos (aéreos e basais reprodutivos) não foram influenciadas ( $\mathrm{P}>0,05)$ pela adubação nitrogenada nos pastos diferidos de capim-piatã. Possivelmente, a baixa contribuição relativa dessas categorias limitou a ocorrência de efeito do nitrogênio. De fato, o nitrogênio modificou apenas a densidade de perfilhos basais vegetativos, que correspondeu à categoria majoritária nos pastos diferidos, com participação relativa de $74 \%$ e $54 \%$ nos pastos manejados com curto e longo período de diferimento, respectivamente.

Com relação aos efeitos do período de diferimento, sua menor duração resultou em pastos diferidos com números de perfilhos basais e aéreos vegetativos maiores $(\mathrm{P}<0,05)$, assim como número de perfilho basal reprodutivo inferior $(\mathrm{P}<0,05)$ (Tabela 3 ). Santos et al. ${ }^{(4)}$, em estudo com $B$. decumbens cv. Basilisk diferida, também verificaram que o período de diferimento tem efeito negativo sobre o número de perfilho vegetativo e positivo sobre o número de perfilho reprodutivo no pasto. A maior luminosidade na base das plantas com curto período de diferimento estimula o perfilhamento, ou seja, o aparecimento de novos perfilhos vegetativos, conforme já discutido. De outro modo, a alta competição por luz no dossel diferido por longo período favorece a continuidade do desenvolvimento de parte dos perfilhos pré-existentes e mais velhos, que passam para o estádio reprodutivo, seguindo o ciclo fenológico normal da gramínea.

Como as categorias de perfilhos vegetativos e reprodutivos têm características estruturais e de valor distintas $^{(6,23)}$, alterações em suas densidades populacionais geram modificações na estrutura do pasto, com consequências sobre o comportamento ingestivo, o consumo e o desempenho de bovinos em pastagens diferidas ${ }^{(24)}$. Nesse sentido, a adoção de longo período de diferimento (127 dias), somada à aplicação de elevadas doses de nitrogênio, pode comprometer a formação dos perfilhos 
jovens, que são as unidades de crescimento do pasto mais responsivas às ações de manejo ${ }^{(25)}$, bem como de melhor morfologia e valor nutritivo ${ }^{(23)}$.

Adicionalmente, longo período de diferimento e dose alta de nitrogênio também podem resultar em pastos menos favoráveis ao consumo animal, em virtude da maior ocorrência de perfilhos em estádio reprodutivo, que apresentam limitações nutricionais ${ }^{(23)}$ e também tendem a tombar durante o período de pastejo, elevando as perdas de forragem ${ }^{(4)}$.

Como o pasto de gramíneas é formado por uma população de perfilhos, as características estruturais dos perfilhos determinam a estrutura do pasto, ou seja, a forma como a forragem é ofertada para o animal em pastejo. Desse modo, torna-se relevante conhecer as modificações morfológicas dos perfilhos individuais frente às variações de período e de dose de nitrogênio em pastagens diferidas.

Em geral, o nitrogênio aumentou linearmente $(\mathrm{P}<0,05)$ os comprimentos da lâmina foliar e do colmo do perfilho vegetativo de capim-piatã (Tabela 4). Isso ocorre devido ao estímulo do nitrogênio sobre o desenvolvimento do pasto. Nesse sentido, perfilhos mais desenvolvidos necessitam de um órgão estrutural, o colmo, mais robusto para sustentar o maior peso da planta. Ademais, no pasto mais desenvolvido, maior é a competição intraespecífica por luz entre os perfilhos, o que desencadeia o alongamento do colmo, uma forma de expor as novas lâminas foliares na parte superior do dossel, onde a luminosidade é maior. É possível que o colmo mais comprido do capim-piatã tenha aumentado a distância entre o meristema apical e o ápice do perfilho, o que fez com que o tempo de alongamento foliar fosse maior, resultando em lâminas foliares mais compridas ${ }^{(26)}$.

A adubação nitrogenada não modificou o número de folhas vivas e mortas ( $\mathrm{P}>0,05)$. Por outro lado, poder-se-ia esperar incremento do número de folhas mortas com a adubação nitrogenada, considerando-se que o nitrogênio estimula o aparecimento de folhas no perfilho e, assim, aquelas formadas primeiramente tendem a morrer mais precocemente, o que elevaria o número de folhas mortas no perfilho. Possivelmente, o desprendimento de folhas mortas no perfilho de capim-piatã pode ter sido o fator responsável pela ausência de efeito do nitrogênio sobre essa característica.

A estrutura do perfilho basal vegetativo também foi alterada pela duração do período de diferimento. Nesse contexto, quando cotejado ao curto, o longo período de diferimento prejudicou a morfologia desta classe de perfilho, porque resultou em colmo mais comprido $(\mathrm{P}<0,05)$ e em maior $(\mathrm{P}<0,05)$ número de folhas mortas, a despeito do maior $(\mathrm{P}<0,05)$ comprimento da lâmina foliar (Tabela 4).

A morfologia do perfilho basal reprodutivo foi alterada pela aplicação de nitrogênio apenas no que diz respeito ao número de lâmina foliar morta, que reduziu linearmente $(\mathrm{P}<0,05)$ no pasto submetido ao curto período de diferimento (Tabela 5). É provável que o fato de esta última categoria de perfilho ser de maior estádio de desenvolvimento a torna menos responsiva às ações de manejo. Contudo, o incremento do número de lâmina foliar morta pode estar relacionado ao maior sombreamento no interior do dossel adubado. Nessa situação, as folhas mais velhas e localizadas na porção basal do pasto são sombreadas pelas folhas mais jovens e localizadas no estrato superior do perfilho. Com isso, as folhas mais velhas ultrapassam o ponto de compensação de luz, condição em que a taxa de fotossíntese é igual à de respiração, o que ocasiona a senescência foliar ${ }^{(27)}$. 
Tabela 4. Características estruturais de perfilhos basais vegetativos do capim-piatã diferido em dois períodos e com quatro doses de nitrogênio

\begin{tabular}{|c|c|c|c|c|c|c|}
\hline \multirow[t]{2}{*}{$\begin{array}{l}\text { Período de } \\
\text { diferimento }\end{array}$} & \multicolumn{4}{|c|}{ Dose de nitrogênio (kg/ha) } & \multirow[b]{2}{*}{ Equação } & \multirow[b]{2}{*}{$\mathbf{r}^{2}$} \\
\hline & 0 & 40 & 80 & 120 & & \\
\hline \multicolumn{7}{|c|}{ Comprimento final da lâmina foliar $(\mathrm{cm})$} \\
\hline Curto & $16,4 \mathrm{~b}$ & $19,5 \mathrm{~b}$ & $23,8 \mathrm{~b}$ & $30,0 \mathrm{a}$ & $\hat{\mathrm{Y}}=15,65+0,11266^{*} \mathrm{~N}$ & 0,97 \\
\hline Longo & $28,1 \mathrm{a}$ & $28,6 \mathrm{a}$ & $33,0 \mathrm{a}$ & $30,1 \mathrm{a}$ & $\bar{Y}=30,0$ & - \\
\hline \multicolumn{7}{|c|}{ Comprimento do colmo $(\mathrm{cm})$} \\
\hline Curto & $20,8 \mathrm{~b}$ & $19,6 \mathrm{~b}$ & $23,9 \mathrm{~b}$ & $27,4 \mathrm{~b}$ & $\bar{Y}=22,9$ & - \\
\hline Longo & $46,3 \mathrm{a}$ & $49,4 \mathrm{a}$ & $56,3 \mathrm{a}$ & 63,3 a & $\hat{\mathrm{Y}}=45,16+0,14442^{*} \mathrm{~N}$ & 0,97 \\
\hline \multicolumn{7}{|c|}{ Número de folha viva (folha/perfilho) } \\
\hline Curto & 5,3 & 4,4 & 4,3 & 4,7 & $\bar{Y}=4,7$ & - \\
\hline Longo & 5,1 & 5,1 & 4,6 & 4,9 & $\bar{Y}=4,9$ & - \\
\hline \multicolumn{7}{|c|}{ Número de folha morta (folha/perfilho) } \\
\hline Curto & $1,9 \mathrm{a}$ & $1,6 \mathrm{~b}$ & $1,6 \mathrm{~b}$ & $1,5 \mathrm{~b}$ & $\bar{Y}=1,6$ & - \\
\hline Longo & $2,5 \mathrm{a}$ & $2,9 \mathrm{a}$ & $3,0 \mathrm{a}$ & $3,1 \mathrm{a}$ & $\bar{Y}=2,9$ & - \\
\hline
\end{tabular}

Tabela 5. Características estruturais de perfilhos basais reprodutivos do capim-piatã diferido em dois períodos e com quatro doses de nitrogênio

\begin{tabular}{|c|c|c|c|c|c|c|}
\hline \multirow{2}{*}{$\begin{array}{l}\text { Período de } \\
\text { diferimento }\end{array}$} & \multicolumn{4}{|c|}{ Dose de nitrogênio (kg/ha) } & \multirow{2}{*}{ Equação } & \multirow{2}{*}{$\mathbf{R}^{2}$} \\
\hline & 0 & 40 & 80 & 120 & & \\
\hline \multicolumn{7}{|c|}{ Comprimento final da lâmina foliar $(\mathrm{cm})$} \\
\hline Curto & $10,1 \mathrm{~b}$ & $14,2 \mathrm{~b}$ & $14,3 \mathrm{~b}$ & $14,0 \mathrm{~b}$ & $\bar{Y}=13,1$ & - \\
\hline Longo & $22,5 \mathrm{a}$ & $21,3 \mathrm{a}$ & $23,0 \mathrm{a}$ & $24,9 \mathrm{a}$ & $\bar{Y}=22,9$ & - \\
\hline \multicolumn{7}{|c|}{ Comprimento do colmo $(\mathrm{cm})$} \\
\hline Curto & $62,2 \mathrm{~b}$ & $73,5 \mathrm{~b}$ & $69,9 \mathrm{~b}$ & $62,6 \mathrm{~b}$ & $\bar{Y}=67,0$ & - \\
\hline Longo & $\begin{array}{c}137,8 \\
\mathrm{a}\end{array}$ & $130,8 \mathrm{a}$ & $140,6 \mathrm{a}$ & $142,2 \mathrm{a}$ & $\bar{Y}=137,9$ & - \\
\hline \multicolumn{7}{|c|}{ Número de folha viva (folha/perfilho) } \\
\hline Curto & $4,8 \mathrm{a}$ & $3,6 \mathrm{~b}$ & $3,6 \mathrm{~b}$ & $3,6 \mathrm{~b}$ & $\bar{Y}=3,9$ & - \\
\hline Longo & $5,0 \mathrm{a}$ & $5,2 \mathrm{a}$ & $5,6 \mathrm{a}$ & $5,3 \mathrm{a}$ & $\bar{Y}=5,3$ & - \\
\hline \multicolumn{7}{|c|}{ Número de folha morta (folha/perfilho) } \\
\hline Curto & 2,1 & 3,5 & 3,6 & 4,1 & $\hat{\mathrm{Y}}=2,43+0,01520 * \mathrm{~N}$ & 0,85 \\
\hline Longo & 1,9 & 3,1 & 3,0 & 3,2 & $\bar{Y}=2,8$ & - \\
\hline
\end{tabular}

Quanto ao diferimento, o longo período promoveu maiores $(\mathrm{P}<0,05)$ comprimentos de colmo e de lâminas foliares no perfilho basal reprodutivo (Tabela 5), semelhantemente ao ocorrido e já discutido para o perfilho basal vegetativo (Tabela 4). Porém o maior $(\mathrm{P}<0,05)$ número de folhas vivas nos perfilhos sob longo período de diferimento não era esperado. 
Diante dos resultados apresentados, fica evidente que, além de elevar o número de perfilhos reprodutivos no pasto diferido (Tabela 3), o longo período de diferimento também acarreta pior estrutura do pasto diferido via modificações deletérias na morfologia do perfilho vegetativo (Tabela 4). Adicionalmente, doses elevadas de nitrogênio também podem estimular o desenvolvimento demasiado do pasto (Tabela 2), com aumento do sombreamento na base do dossel, o que diminui o aparecimento de unidades de crescimento do pasto, quais sejam os perfilhos jovens (Tabela 3).

\section{Conclusões}

Para obtenção de pasto com estrutura apropriada ao consumo animal durante o inverno, a Brachiaria brizantha cv. Piatã pode ser diferida por 80 dias, com aplicação de $80 \mathrm{~kg} / \mathrm{ha}$ de nitrogênio no início do período de diferimento.

\section{Referências}

1. Moreira LM, Martuscello JÁ, Fonseca DM, Mistura C, Moraes RV, Ribeiro Junior JI. Perfilhamento, acúmulo de forragem e composição bromatológica do capim-braquiária adubado com nitrogênio. Revista Brasileira de Zootecnia, v.38, n.9, p.1675-1684, 2009.

2. Gimenes FMA, Da Silva SC, Fialho CA, Gomes MB, Berndt A, Gerdes L, Colozza MT. Ganho de peso e produtividade animal em capim-marandu sob pastejo rotativo e adubação nitrogenada. Pesquisa Agropecuária Brasileira, v.46, n.7, p.751-759, jul. 2011.

3. Nantes NN, Euclides VPB, Montagner DB, Lempp B, Barbosa RA, Gois PO. Desempenho animal e características de pastos de capim-piatã submetidos a diferentes intensidades de pastejo Pesquisa Agropecuária Brasileira, v.48, n.1, p.114-121, 2013.

4. Santos MER, Fonseca DM, Euclides VPB, Nascimento Junior D, Queiroz DS, Ribeiro Junior JI. Características estruturais e índice de tombamento de Brachiaria decumbens cv. Basilisk em pastagens diferidas. Revista Brasileira de Zootecnia, v.38, p.626-634, 2009a.

5. Signoretti RD, Moraes JCG, Pessim, B, Souza, FHM, Souza LA, Modesto RT. Desempenho produtivo de novilhas leiteiras suplementadas na época da seca em pastagens diferidas, sob duas taxas de lotação. Boletim de Indústria animal, v. 70, n.1, p.28-37, 2013.

6. Santos MER, Fonseca DM, Balbino EM, Silva SP, Gomes VM. Características estruturais de perfilhos vegetativos e reprodutivos em pastos diferidos de capim-braquiária. Ciência Animal Brasileira, v. 11, n. 3, p. 492-502, 2010a.

7. Fagundes JL, Fonseca DM, Mistura C, Moraes RV, Vitor CMT, Gomide JA, Nascimento Júnior D, Casagrande DR, Costa LT. Características morfogênicas e estruturais do capim-braquiária em pastagem adubada com nitrogênio avaliadas nas quatro estações do ano. Revista Brasileira de Zootecnia, v. 35, n. 1, p. 21-29, 2006.

8. Santos MER, Fonseca DM, Balbino EM, Santos JPI, Silva SP. Capim braquiária diferido e adubado com 
nitrogênio: produção e características da forragem. Revista Brasileira de Zootecnia, v.38, p. 650-656, 2009 b.

9. Souza BML, Santos MER, Vilela HH, Silveira MCT, Rocha GO, Freitas CAS, Silva NMA, Nascimento Junior, D. Piata palisade grass deferred with two distinct initial heights: luminous environment and tillering dynamics. Revista Brasileira de Zootecnia, v.42, n.1, p.36-43, 2013.

10. Empresa Brasileira de Pesquisa Agropecuária - EMBRAPA. Serviço Nacional de Levantamento e Conservação de Solos. Sistema brasileiro de classificação de solos. 2.ed. Rio de Janeiro: Embrapa Solos, 2006. 306p.

11. Köpen W. Climatologia.Buenos Aires: Gráfica Panamericana, 1948. 478p.

12. Souza BML, Vilela HH, Santos AL, Santos MER, Nascimento Junior D, Assis CZ, Faria BD, Rocha GO. Piata palisadegrass deferred in the fall: effects of initial height and nitrogen in the sward structure. Revista Brasileira de Zootecnia, v.41, n.5, p.1134-1139, 2012.

13. Vilela HH, Souza BML, Santos MER, Santos AL, Assis CZ, Rocha GO, Faria BD, Nascimento Junior D. Forage mass and structure of piatã grass deferred at different heights and variable periods. Revista Brasileira de Zootecnia, v.41, n.7, p.1625-1631, 2012.

14. GOMES, J.M. SAEG: sistema de análises estatísticas e genéticas. Versão 5.0. Viçosa: UFV, 1992. 100p.

15. Martuscello JÁ, Fonseca DM, Nascimento Junior D, Santos PM, Cunha DNFV, Moreira LM. Características morfogênicas e estruturais do capim-massai submetido a adubação nitrogenada e a desfolhação. Revista Brasileira de Zootecnia, v.35, n.3, p.665-671, 2006.

16. Sbrissia AF, Da Silva SC. Comparação de três métodos para estimativa do índice de área foliar em pastos de capim-marandu sob lotação contínua. Revista Brasileira de Zootecnia, v.37, n.2, p.212-220, 2008a.

17. Paula CCL, Euclides VPB, Montagner DB, Lempp B, Barbosa RA, Goes PO. Estrutura do dossel, consumo e desempenho animal em pastos de capim-marandu sob lotação contínua. Arquivo Brasileiro de Medicina Veterinária e Zootecnia, v.64, n.1, p.169-176, Feb. 2012.

18. Santos MER, Fonseca DM, Gomes VM, Balbino EM, Magalhães MA. Estrutura do capim-braquiária durante o diferimento da pastagem. Acta Scientiarum. Animal Sciences, v. 32, n. 2, p. 139-145, 2010b.

19. Bernardes MS. Fotossíntese no dossel das plantas cultivadas. In: Castro PRC, Ferreira SO, Yamada T. Ecofisiologia da produção agrícola. Piracicaba: Associação Brasileira de Pesquisa de Potassa e do Fosfato, 1987. p.13-48.

20. Pereira LET, Paiva AJ, Da Silva SC, Caminha FO, Guarda VD, Pereira PM. Sward structure of Marandu palisadegrass subjected to continuous stocking and nitrogen-induced rhythms of growth. Scientia Agricola, v.67, n.5, p.531-539, 2010.

21. Deregibus VA, Sanchez RA, Casal JJ. Effects of light quality on tiller production in Lolium spp. Plant Physiology, v.27, p.900-912, 1983.

22. Sbrissia AF, Da Silva SC. Compensação tamanho/densidade populacional de perfilhos em pastos de capim-marandu. Revista Brasileira de Zootecnia, v. 37, n. 1, p. 35-47, 2008b.

23. Santos MER, Fonseca DM, Balbino EM, Silva SP, Monerat JPIS. Valor nutritivo de perfilhos e componentes morfológicos em pastos de capim-braquiária diferidos e adubados com nitrogênio. Revista Brasileira de Zootecnia, v.39, n.9, p.1919-1927, 2010c.

24. Difante G dos S, Euclides VPB, Nascimento Júnior, D do, Da Silva SC, Torres Júnior RA de A, Sarmento DO de L. Ingestive behavior, herbage intake and grazing efficiency of beef cattle steers on Tanzania guineagrass subjected to rotational stocking managements. Revista Brasileira de Zootecnia, v.38, 
p.1001-1008, 2009.

25. Paiva AJ, Da Silva SC, Pereira LET, Caminha FO, Pereira PM. Morphogenesis on age categories of tillers in marandu palisadegrass. Scientia Agrícola, v. 68, p. 626-631, 2011.

26. Skinner RH, Nelson CJ. Elongation of the grass leaf and its relationship phillochron. Crop Science, v.35, n.1, p.4-10, 1995.

27. Taiz L, Zeiger E. Fisiologia Vegetal. Porto Alegre: Artmed, 3 ed., 2004. 719p. 